\title{
A Safe and Effective Method for Treatment of Chronic Subdural Haematoma
}

\author{
Mustafa Gurelik, Adem Aslan, Bilge Gurelik, Unal Ozum, \\ Özen Karadag, H. Zafer Kars
}

\begin{abstract}
Objective: Burr-hole irrigation and burr-hole drainage without irrigation are the most popular methods for treatment of chronic subdural haematoma. It is not well known if irrigation is necessary or which method has a higher recurrence rate. We compared the recurrence rates of those two methods. Materials and Methods: Forty-two patients were treated by burr-hole irrigation (irrigation group), whereas 38 patients were treated by burr-hole drainage (drainage group). Recurrence rate and its relation with sex, age, haematoma localization and aetiology were investigated in both groups. Results: There was no significant difference between recurrence rates of the two groups. There was also no correlation between recurrence rate and age, sex, haematoma localization, or aetiology. Conclusions: There was no significant difference between recurrence rates of the two groups. Since the burr-hole drainage method is simpler to carry out, its use may be preferable.
\end{abstract}

RÉSUMÉ: Une méthode de traitement sûre et efficace de l'hématome sous-dural chronique. Objectif : Les méthodes de traitement les plus populaires de l'hématome sous-dural chronique sont l'irrigation par trou de trépan et le drainage par trou de trépan sans irrigation. On ne sait pas vraiment si l'irrigation est nécessaire ou quelle méthode comporte le taux de récidive le plus élevé. Nous avons comparé le taux de récidive de ces deux méthodes de traitement. Matériels et méthodes : Quarante-deux patients ont subi une irrigation par trou de trépan (groupe avec irrigation) et 38 patients ont subi un drainage par trou de trépan (groupe avec drainage). Nous avons examiné le taux de récidive et sa relation au sexe, à l'âge, à la localisation de l'hématome et à son étiologie. Résultats : Nous n'avons pas observé de différence significative entre le taux de récidive des deux groupes ou de corrélation entre le taux de récidive et l'âge, le sexe, la localisation de l'hématome ou son étiologie. Conclusions : Il n'y avait pas de différence significative entre le taux de récidive des deux groupes. Comme la méthode de drainage par trou de trépan est plus simple, elle est probablement préférable.

Can. J. Neurol. Sci. 2007; 34: 84-87

Although chronic subdural haematoma (CSDH) is a curable disease and has low morbidity and mortality, high recurrence rates challenge neurosurgical practice. The rate of recurrence of chronic subdural haematoma after surgery is 3.7 to $22.2 \%$. $^{1-3}$ Lower $(0.35-8.4 \%)^{4-6}$ and higher $(16 \text { and } 25 \%)^{7,8}$ recurrence rates were reported in recent studies.

Although there are several surgical procedures for $\mathrm{CSDH}$, burr-hole irrigation with closed-system drainage is now generally accepted as the treatment method. ${ }^{9-12}$ Different recurrence rates were reported in studies comparing burr-hole irrigation and burr-hole drainage methods.,5,7,8,10 Enlarged craniectomy and extended craniotomy are rarely used methods and are reserved for instances of acute rebleeding with solid hematoma. ${ }^{3}$
From the Department of Neurosurgery (MG, UO, OK, HZK), Department of Anaesthesiology (BG), Faculty of Medicine, Cumhuriyet University, Sivas, Turkey; Department of Neurosurgery (AA), Faculty of Medicine, Kocatepe University, Afyon, Turkey.

Received MAy 1, 2006. AcCEPTED in FinAl form November 23, 2006 Reprint requests to: Mustafa Gurelik, Beyin ve Sinir Cerrahisi AD, Cumhuriyet Üniversitesi Hastanesi, 58140 Sivas, Turkey. 


\section{Materials AND Methods}

Between 2001 and 2004, 80 patients with CSDH were treated surgically at Cumhuriyet University Hospital. This study was approved by the institutional ethical committee at Cumhuriyet University and informed consent was obtained from all patients. In this prospective study, patients were assigned by simply random sampling method to each group and 42 patients $(52.5 \%)$ underwent burr-hole irrigation (irrigation group) while 38 patients $(47.5 \%)$ underwent burr-hole drainage (drainage group). There were 28 males and 14 females and the mean age of the patients was 58.4 years in the irrigation group. There were 22 males and 16 females and the mean age of the patients was 59.2 years in the drainage group. Head trauma had been ascertained in $59.5 \%$ of all patients in the irrigation group. Other aetiological factors in irrigation group included dehydration (7.1\%), CNS infection $(2.3 \%)$, shunt overdrainage $(2.3 \%)$, and alcoholism $(2.3 \%)$. In the irrigation group, $21.5 \%$ of all cases were idiopathic (Figure 1). In the drainage group, aetiological factors were trauma $(63.1 \%)$, dehydration $(7.9 \%)$, and CNS infection $(2.6 \%)$. Of the cases in the drainage group $23.7 \%$ were idiopathic (Figure 1).

Clinical laboratory studies before surgery included bleeding time, platelet count, prothrombin time, activated partial thromboplastin time, and serum biochemical analysis. Operative technique for burr-hole irrigation was as follows: One or two burr-holes $14 \mathrm{~mm}$ in diameter were drilled. Dura and outer membrane were incised, a $5 \mathrm{~F}$ Nelaton tube was inserted into the cavity, and the haematoma was washed out by warm physiological saline. When the fluid became clear, the irrigation catheter was connected to a sterile bile bag for closed-system drainage without negative pressure. In the burr-hole drainage

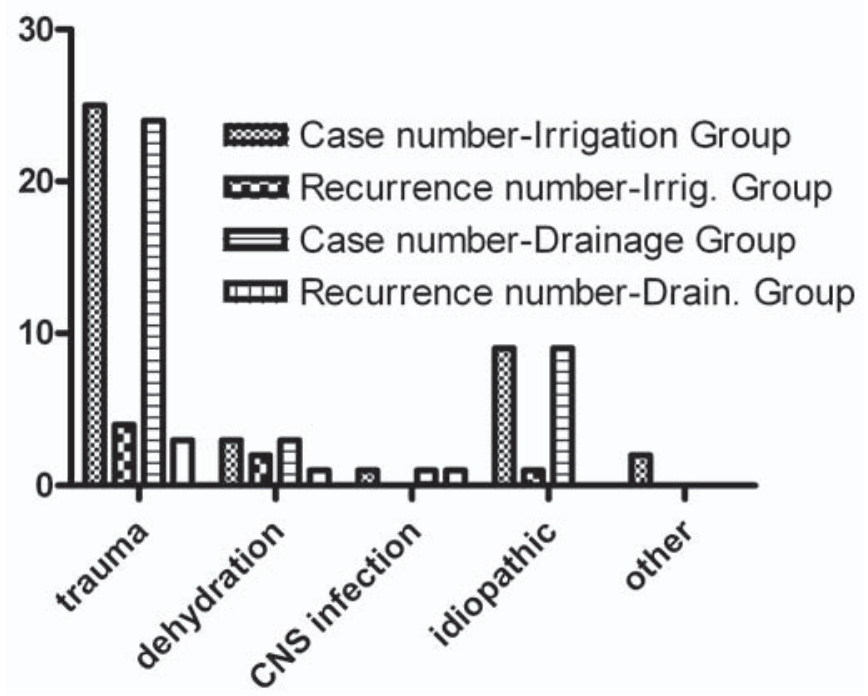

Figure 1: The relationship between etiology and recurrence in groups. Other; shunt over drainage $(n=1)$ and alcoholism $(n=1)$. method, a twist drill hole in $3 \mathrm{~mm}$ diameter was made at the point where the haematoma was thickest. The dura mater was pierced and a silicone catheter was inserted into the haematoma cavity and catheter was connected to an active drainage bag, and no attempt was made to irrigate the subdural space. The draining pressure was -5 to $-10 \mathrm{cmH}_{2} \mathrm{O}$ in this method.

All patients were laid in bed with their heads raised $15^{\circ}$ during drainage. Regardless of residual haematoma volume or presence of subdural air collection on the CT scan, all drainage catheters were removed within 48 hours post surgery. If the symptoms or clinical findings failed to improve or got worse, a CT was performed, and if there was a recurrence of mass effect, a reoperation was carried out. The hospitalization period after surgery in the irrigation and drainage groups were 6 (3-8) and 11 (7-14) days respectively. Mean follow-up period was 8 months (3-24 months). For statistical analysis, a chi-square test was used with commercially available software. Recurrence rates and the relation of the recurrence with factors such as age, sex, haematoma and aetiology were evaluated statistically.

\section{RESULTS}

Recurrence rate was $19 \%$ (8 patients) in the irrigation group, $10.5 \%$ (4 patients) in the drainage group (Figure 3 ). There was no significant difference between recurrence rates of the two groups $(p>0.05)$. The relation of recurrence with age, sex, aetiology, side of haematoma, localization of haematoma was investigated in both groups (Figure 1 and Figure 2). Recurrence occurred in six male and two female patients in irrigation group. In the drainage group, recurrence was seen in four male patients. The recurrence rate as to aetiology was as follows: Irrigation Group; Trauma $16 \%$, dehydration $66.6 \%$, idiopathic $11.1 \%$ and

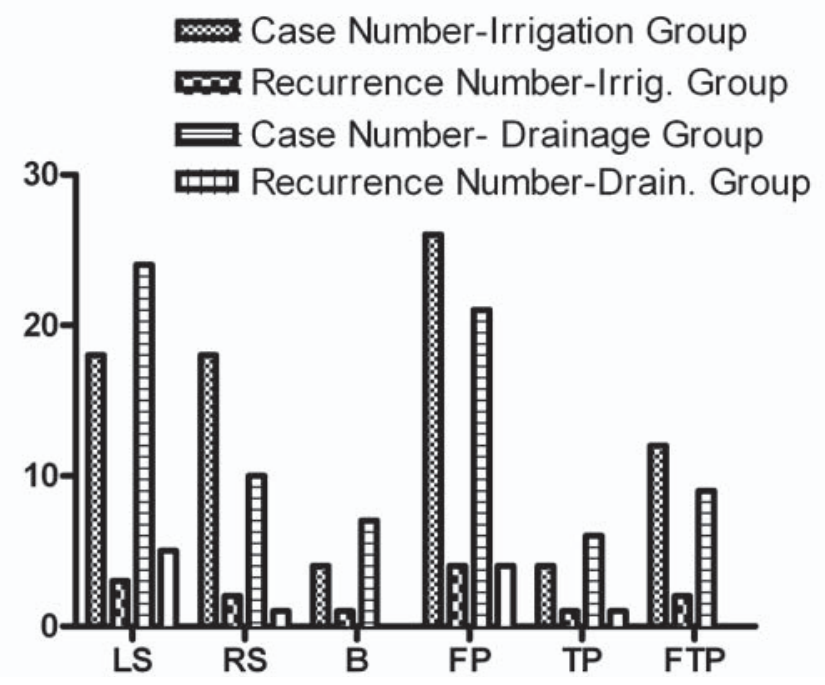

Figure 2: The relationship between $C S D H$ localization and recurrence in groups. LS, left sided; RS, right sided; B, bilateral; FP, frontoparietal; TP, temporo-parietal; FTP, fronto-temporo-parietal. 
Table: Comparison of the features in both groups

\begin{tabular}{lll}
\hline & $\begin{array}{l}\text { Drainage } \\
\text { group }\end{array}$ & $\begin{array}{l}\text { Irrigation } \\
\text { group }\end{array}$ \\
Case number & 42 & 38 \\
Mean age & 58.4 & 59.2 \\
Sex M/F & $28 / 14$ & $22 / 16$ \\
Recurrence rate & $8(19 \%)$ & $4(10.5 \%)$ \\
\hline
\end{tabular}

CNS infection, shunt over drainage, alcoholism $0 \%$. Drainage Group; trauma $12.5 \%$, dehydration $33.3 \%$, CNS infection 100 $\%$ and idiopathic $0 \%$. As the numbers of patients with infection, dehydration, shunt over drainage and alcoholism in the irrigation group (Figure 1) and dehydration and CNS infection in the drainage group (Figure 1) were low, statistical analysis was not performed. There was no significant difference between recurrence rate and haematoma location $(\mathrm{p}>0.05)$ in either group (Figure 2). There was also no significant recurrence rate between the patients were performed single or multiple burr-holes in the irrigation group.

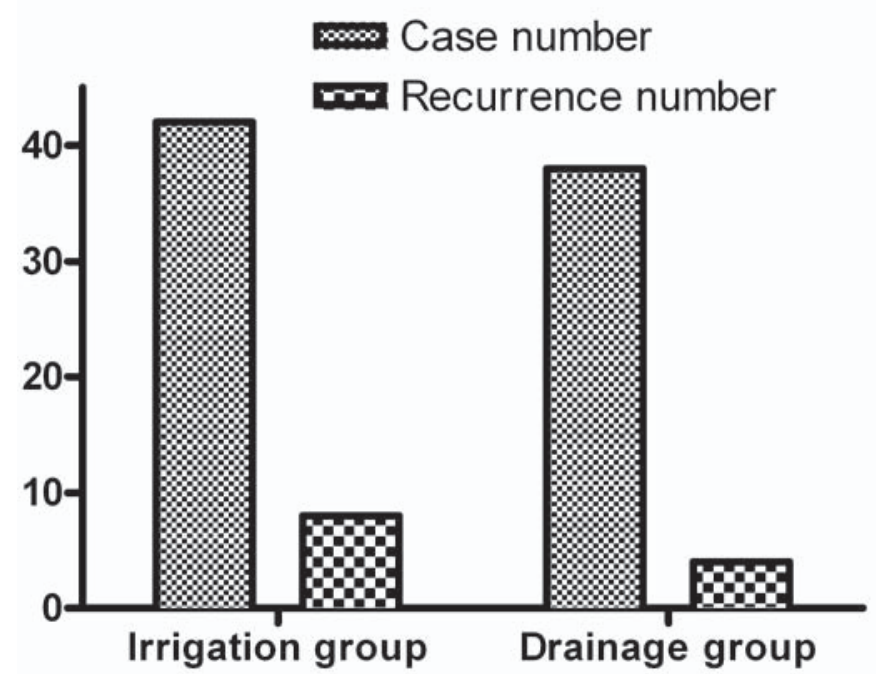

Figure 3: The relation between surgical technique and recurrence in both groups.

\section{DISCUSSION}

In our investigation, although the recurrence rate in the drainage group was lower than in the irrigation group, the difference was not statistically significant. The recurrence rate in drainage group was $10.4 \%$ which, is similar to the results reported in recent studies. ${ }^{6-8,10,12,13}$ Although CSDH is common in neurosurgical practice and usually cured, recurrence has not been eliminated. Irrigation and drainage with one or two burrholes is the accepted standard surgical treatment. .,8,10 $^{-1}$

We also analysed the factors contributing to the recurrence such as age, sex, location of haematoma, aetiology and technique. There was no significant difference between recurrent and non-recurrent cases regarding sex, age, haematoma location, aetiology and surgical technique. These data show that preoperative prediction of recurrence of CSDH is not possible and burr-hole drainage technique for $\mathrm{CSDH}$ is as effective as burr-hole irrigation. Burr-hole irrigation often allows entrance of air into the subdural space. Pneumocephalus, even in the absence of tension, increases morbidity and headache. ${ }^{12}$ A variety of catheters have been inserted into the subdural space, either through burr-holes or twist drill holes. These may penetrate brain parenchyma or injure tenuous bridging veins. Application of negative pressure to a catheter in the subdural space may result plugging by brain tissue or meninges. Larger catheters may provoke seizures., ${ }^{4,8,12}$ Burr-hole drainage technique has lower incidence as to these complications and hospitalization time is shorter. ${ }^{8}$ However, incomplete drainage in patients with multiple haematoma cavities may be expected in the burr-hole drainage technique. ${ }^{7}$

In this study, our small sample size is a limitation of the data. Therefore, although there was an apparent difference between recurrence rates of the two groups, this difference was not statistically significant.

In conclusion, although recurrence rate difference between both techniques is similar, the burr-hole drainage technique is as safe and effective as burr-hole irrigation in CSDH. Additionally, it was reported that the incidence of the complications of this approach is lower and it requires shorter hospitalization time. ${ }^{7}$

\section{ACKNOWLEDGEMENTS}

The authors wish to thank to Dr. Ziynet Çinar for helping with the statistical analysis of this study.

\section{REFERENCES}

1. Ernestus RI, Beldzinski P, Lanfermann H, Klug N. Chronic subdural hematoma: surgical treatment and outcome in 104 patients. Surg Neurol. 1997;48:220-5.

2. El-Kadi H, Miele VJ, Kaufman HH. Prognosis of chronic subdural hematomas. Neurosurg Clin N Am. 2000;11:553-67.

3. Lee JY, Ebel H, Ernestus RI, Klug N. Various surgical treatments of chronic subdural hematoma and outcome in 172 patients: is membranectomy necessary? Surg Neurol. 2004;61:523-8.

4. Suzuki K, Sugita K, Akai T, Takahata T, Sonobe M, Takahashi S. Treatment of chronic subdural hematoma by closed-system drainage without irrigation. Surgical Neurol. 1998;50:231-4.

5. Kwon T-H, Park Y-K, Lim D-J, Cho TH, Chung YG, Chung HS, et al. Chronic subdural hematoma: evaluation of the clinical significance of postoperative drainage volume. J Neurosurg. 2000;93:796-9.

6. Sambasivan MS. An overview of chronic subdural hematoma: experience with 2300 cases. Surg Neurol. 1997;47:418-22. 
7. Okada Y, Akai T, Okamoto K, Lida T, Takata H, Lizuka H. A comparative study of the treatment of chronic subdural hematoma-burr hole drainage versus burr hole irrigation. Surg Neurol. 2002;57:405-10.

8. Nakajima H, Yasui T, Nishikawa M, Kishi H, Kan M. The role of postoperative patient posture in the recurrence of chronic subdural hematoma: a prospective randomized trial. Surg Neurol. 2002;58:385-7.

9. Hennig R, Kloster R. Burr hole evacuation of chronic subdural haematomas followed by continuous inflow and outflow irrigation. Acta Neurochir. 1999;141:171-6.

10. Nakaguchi H, Tanishima T, Yoshimasu N. Relationship between drainage catheter location and postoperative recurrence of chronic subdural hematoma after burr-hole irrigation and closedsystem drainage. J Neurosurg. 2000;93:791-5.
11. Benes L, Eggers F, Alberti O, Bertalanffy H. A new screw catheter kit for the beside treatment of chronic subdural hematomas. J Trauma. 2002;52:591-4.

12. Asfora WT, Schwebach L. A modified technique to treat chronic and subacute subdural hematoma: technical note. Surg Neurol. 2003;59:329-32.

13. Kuroki T, Katsume M, Harada N, Yamazaki T, Aoki K, Takasu N. Strict closed-system drainage for treating chronic subdural haematoma. Acta Neurochir. 2001;143:1041-4. 